\title{
СРАВНИТЕЛЬНЫЙ ФИЛОГЕНЕТИЧЕСКИЙ АНАЛИЗ КЛИНИЧЕСКИХ ИЗОЛЯТОВ NEISSERIA GONORRHOEAE РОССИИ, СТРАН ЕВРОСОЮЗА И ЯПОНИИ
}

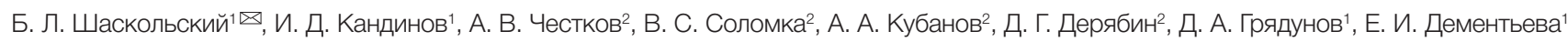

${ }^{1}$ Центр высокоточного редактирования и генетических технологий для биомедицины, Институт молекулярной биологии имени В. А. Энгельгардта Российской академии наук, Москва, Россия

${ }^{2}$ Государственный научный центр дерматовенерологии и косметологии Минздрава России, Москва, Россия

\begin{abstract}
Мониторинг возбудителей инфекционных заболеваний, развивающих множественную устойчивость к антимикробным препаратам, является важной и актуальной задачей. Целью работы являлось генотипирование современных российских клинических изолятов N. gonorrhoеaе по протоколу NG-MAST (Neisseria gonorrhoeae multi-antigen sequence types) и сравнительный филогенетический анализ возбудителя гонококковой инфекции в России, странах EC и Японии. Всего исследовано 822 изолята, собранных в РФ в период с 2013 по 2018 гг. Использовали также данные NG-MAST-типирования из баз данных «PathogenWatch» (страны EC, 1071 образец) и «PubMLST» (Япония, 206 образцов). Изоляты PФ принадлежали к 301 различному NG-MAST типу, наиболее распространенными являлись 807, 228, 1993, 5714, 9476 (8,3\%; 3,3\%; 3,2\%; 3,2\%; 2,7\% соответственно). В РФ обнаружено только 3 изолята (0,4\%) пандемически значимого NG-MAST 1407, характеризующегося множественными детерминантами резистентности к антимикробным препаратам и доминирующего во многих странах мира. Построено филогенетическое древо NG-MAST типов, найденных в России и в европейских странах. Кластерный анализ данных по доле изолятов с уникальными сиквенс-типами и численности населения показал существование двух кластеров (уровень значимости 0,01): первый составили Россия и Япония, второй - европейские страны. Показана тенденция в распределении уникальных сиквенс-типов - их доля тем выше, чем больше численность населения страны. Филогенетический анализ показал генетическую отдаленность наиболее распространенных российских, европейских и японских сиквенс-типов, что указывает на локальный характер формирования и эволюции российской популяции N. gonorrhoeae.
\end{abstract}

Ключевые слова: филогения Neisseria gonorrhoeae, NG-MAST

Финансирование: работа выполнена при поддержке гранта РНФ 17-75-20039 (оценка генетического разнообразия сиквенс-типов) и Соглашения с Министерством науки и высшего образования РФ № 075-15-2019-1660 (сбор и верификация клинических изолятов, определение соответствия уникальных сиквенс-типов и численности населения). Секвенирование изолятов выполнено в ЦКП «Геном» ИМБ PAH (http://www.eimb.ru/ru1/ckp/ccu_genome_c.php).

Вклад авторов: Б. Л. Шаскольский, Е. И. Дементьева, И. Д. Кандинов - проведение исследования, анализ данных, написание статьи; Д. А. Грядунов организация исследования, работа над рукописью; А. В. Честков, В. С. Соломка, А. А. Кубанов, Д. Г. Дерябин - сбор и верификация клинических изолятов, анализ данных

Соблюдение этических стандартов: исследование одобрено этическим комитетом Государственного научного центра дерматовенерологии и косметологии (протокол № 11 от 29 ноября 2019 г.). Отбор биологического материала для исследования был произведен с учетом положений Хельсинской декларации ВМА (2000) и протокола Конвенции Совета Европы о правах человека и биомедицине (1999).

$\checkmark$ Для корреспонденции: Борис Леонидович Шаскольский ул. Вавилова, д. 32, г. Москва, 119991; b.shaskolskiy@biochip.ru

Статья получена: 09.01.2020 Статья принята к печати: 08.02.2020 Опубликована онлайн: 21.02.2020

DOI: 10.24075/vrgmu.2020.009

\section{COMPARATIVE PHYLOGENETIC ANALYSIS OF NEISSERIA GONORRHOEAE CLINICAL ISOLATES IN RUSSIA, EUROPEAN UNION, AND JAPAN}

\author{
Shaskolskiy BL ${ }^{1} \otimes$, Kandinov $\mathrm{ID}^{1}$, Chestkov $\mathrm{AV}^{2}$, Solomka VS², Kubanov $\mathrm{AA}^{2}$, Deryabin DG², Gryadunov DA ${ }^{1}$, Dementieva El ${ }^{1}$
}

' Center for Precision Genome Editing and Genetic Technologies for Biomedicine, Engelhardt Institute of Molecular Biology, Russian Academy of Sciences, Moscow, Russia

2 State Research Center of Dermatovenerology and Cosmetology, Russian Ministry of Health, Moscow, Russia

Surveillance of multidrug-resistant infections is a priority task for contemporary epidemiology. The aim of this study was to genotype modern clinical isolates of N. gonorrhoeae using the NG-MAST technique (Neisseria gonorrhoeae multi-antigen sequence typing) and to compare the phylogeny of the gonococcal pathogens coming from Russia, European Union and Japan. We studied a total of 822 isolates collected in Russia from 2013 through 2018. We also used NG-MAST data from the following databases: PathogenWatch (European Union, 1,071 isolates) and PubMLST (Japan, 206 isolates). Russian isolates represented 301 different NG-MAST types. The most common were types 807, 228, 1993, 5714, and 9476 (8.3\%, 3.3\%, 3.2\%, 3.2\%, and 2.7\%, respectively). There were only 3 isolates $(0.4 \%)$ from Russia that represented the epidemiologically significant sequence type 1407 prevailing in many countries and characterized by multiple determinants of antimicrobial resistance. A phylogenetic tree for the NG-MAST types found in Russia and European countries was constructed. The cluster analysis of the proportion of isolates belonging to unique sequence types and the country population size allowed us to identify 2 clusters (significance level -0.01 ): the first cluster included Russia and Japan, the second, European countries. A distribution pattern was identified for unique sequence types: the greater is the population size, the higher is their proportion. The phylogenetic analysis demonstrated a genetic distance between the most common Russian, European and Japanese sequence types, suggesting that the Russian population of N. gonorrhoeae has been evolving relatively locally.

Keywords: Neisseria gonorrhoeae, NG-MAST, phylogenetic analysis

Funding: the study was supported by the Russian Science Foundation (Project 17-75-20039 on the assessment of genetic diversity of sequence types) and the Ministry of Science and Higher Education of the Russian Federation (Agreement № 075-15-2019-1660 on the collection and verification of clinical isolates and the establishment of the association between the unique sequence types and the population size). The isolates were sequenced at the facilities of the Genome center for collective use (Engelhardt Institute of Molecular Biology; http://www.eimb.ru/ru1/ckp/ccu_genome_c.php).

Author contribution: Shaskolskiy BL, Dementieva EI, Kandinov ID carried out the study, analyzed the data and wrote the manuscript; Gryadunov DA supervised the study and wrote the manuscript; Chestkov AV, Solomka VS, Kubanov AA, Deryabin DG collected and verified clinical isolates, analyzed the obtained data.

Compliance with ethical standards: the study was approved by the Ethics Committee of the State Research Centre of Dermatovenerology and Cosmetology (Protocol № 11, dated November 29, 2019). Specimens were collected in compliance with the Declaration of Helsinki (2000) and the European Convention on Human Rights and Biomedicine (1999).

Correspondence should be addressed: Boris L. Shaskolskiy

Vavilova, 32, Moscow, 119991; b.shaskolskiy@biochip.ru

Received: 09.01.2020 Accepted: 08.02.2020 Published online: 21.02.2020

DOI: 10.24075/brsmu.2020.009 
Методы молекулярно-генетического типирования, выявляющие внутривидовую вариабельность бактериальных патогенов, с начала XXI в. активно используют для проведения эпидемиологических исследований [1]. Особую актуальность типирование приобрело для мониторинга возбудителей инфекционных заболеваний, развивающих множественную устойчивость к антимикробным препаратам, в частности, возбудителя гонореи Neisseria gonorrhoeae. Всемирная организация здравоохранения (ВОЗ) включила N. gonorrhoeae в список из 12 патогенов, представляющих глобальную угрозу и требующих безотлагательной разработки новых лекарственных препаратов [2].

Задачу контроля и слежения за глобальным и региональным распространением эпидемически значимых, в том числе мультирезистентных, клонов N. gonorrhoeae решают такими методами молекулярного типирования, как NG-MAST (Neisseria gonorrhoeae multi-antigen sequence typing) и MLST (Multilocus sequence typing) [3, 4], а также полногеномным секвенированием (WGS) [5]. Наиболее полная информация о филогении исследуемых клинических изолятов может быть получена с использованием WGS, однако применение этого подхода в рутинной практике пока ограничено его относительно высокой стоимостью и требованиями к качеству анализируемого образца ДНK. Методом MLST, первоначально разработанным для молекулярного типирования N. meningitidis, анализируют гены, более консервативные, чем гены porB и tbpB, используемые в NG-MAST-типировании. В связи с этим NG-MAST остается основным и широко используемым методом, позволяющим исследовать эволюцию патогена и определять пути распространения инфекции $[4,6]$; показана высокая разрешающая способность метода при анализе клинических изолятов $[7,8]$.

Метод NG-MAST основан на определении нуклеотидных последовательностей вариабельных участков двух генов, кодирующих трансмембранный белок порин (porB) и трансферринсвязывающий белок (tbpB). По результатам их секвенирования каждой уникальной последовательности присваивают оригинальный номер аллеля и каждой совокупности аллелей - номер сиквенс-типа (ST). По мере выявления новых аллелей их перечень постоянно дополняют, и к настоящему времени (январь 2020 г.) в базе данных www.ng-mast.net представлено более 11000 аллелей porB и свыше 2900 аллелей tbpB, определяющих существование более 19500 NG-MAST типов.

Целью исследования являлись NG-MAST-типирование современных российских клинических изолятов N. gonorrhoeae и сравнительный филогенетический анализ возбудителей гонококковой инфекции в России, странах Европейского Союза и Японии.

\section{МАТЕРИАЛЫ И МЕТОДЫ}

Клинические изоляты N. gonorrhoeae (822 образца) получены Государственным научным центром дерматовенерологии и косметологии (Москва) из 17 регионов Российской Федерации в рамках долговременной программы мониторинга гонококковой инфекции RUGASP (Russian Gonococcal Antimicrobial Surveillance Programme). Изоляты собраны в период с 2013 по 2018 г. Регионы РФ включали Архангельскую, Астраханскую, Брянскую, Иркутскую, Калужскую, Новосибирскую, Омскую, Пензенскую, Псковскую, Рязанскую, Томскую и Челябинскую области, г. Москву, Ставропольский край, Республику Татарстан, Республику Тыва и Чувашскую Республику (таким образом, были охвачены 7 из 8 федеральных округов РФ, кроме Дальнего Востока). Образцы поступали из специализированных медицинских организаций дерматовенерологического просиля, каждый образец от отдельного пациента. Количество клинических изолятов варьировало в зависимости от плотности населения и показателей заболеваемости гонококковой инфекцией в регионе, в относительных величинах составляя 1-10\% от общего количества зарегистрированных случаев заболевания, а в абсолютных - 5-35 штаммов в год. Сбор клинических изолятов, их транспортировка, культивирование, верификация и хранение подробно описаны [9-11]. Данные по количеству проанализированных клинических изолятов для каждого года исследования представлены в табл. 1.

Молекулярное типирование N. gonorrhoeae проводили путем анализа нуклеотидных последовательностей

Таблица 1. Наиболее часто встречающиеся NG-MAST-типы в России (2013-2018 гг.)

\begin{tabular}{|c|c|c|c|}
\hline Год & $\begin{array}{c}\text { Число проанализированных клинических изолятов } \\
\text { (число выявленных сиквенс-типов) }\end{array}$ & $\begin{array}{l}\text { Наиболее распространенные } \\
\text { сиквенс-типы }\end{array}$ & $\begin{array}{l}\text { Доля образцов данного } \\
\text { сиквенс-типа, \% }\end{array}$ \\
\hline \multirow{3}{*}{2013} & \multirow{3}{*}{$160(81)$} & 807 & 13,1 \\
\hline & & $1152^{*}$ & 5,6 \\
\hline & & $5941^{*}$ & 3,7 \\
\hline \multirow{3}{*}{2015} & \multirow{3}{*}{$123(57)$} & $9476^{\star}$ & 11,4 \\
\hline & & 807 & 8,1 \\
\hline & & $1544^{\star}, 571$ & 4,9 \\
\hline \multirow{3}{*}{2016} & \multirow{3}{*}{261 (128) } & 807 & 6,5 \\
\hline & & $5714^{*}$ & 6,1 \\
\hline & & 1993 & 4,6 \\
\hline \multirow{3}{*}{2017} & \multirow{3}{*}{$127(63)$} & 807 & 10,2 \\
\hline & & $1751^{*}$ & 6,3 \\
\hline & & $13058^{*}$ & 5,5 \\
\hline \multirow{3}{*}{2018} & \multirow{3}{*}{$151(67)$} & $228^{*}$ & 14,6 \\
\hline & & $14942^{*}$ & 5,3 \\
\hline & & $807,1993,14020^{*}$ & 4,6 \\
\hline
\end{tabular}

Примечание: * — NG-MAST-типы, уникальные для России. 
вариабельных участков генов porB (490 пн) и tbpB (390 пн) в соответствии с протоколом NG-MAST [12]. После первого раунда ПЦР-амплификации и очистки полученные фрагменты ДНК секвенировали по Сэнгеру с использованием 3730xl Genetic Analyser (Applied Biosystems; США). Определенные последовательности аллелей сравнивали с последовательностями из базы данных NGMAST database (www.ng-mast.net), и делали заключение о принадлежности исследуемого клинического изолята к определенному сиквенс-типу. Обнаруженные новые последовательности аллелей porB и tbpB или их сочетания регистрировали в указанной выше международной базе данных с присвоением номеров NG-MAST.

При характеристике образцов N. gonorrhoeae из стран EC использовали данные NG-MAST типирования представленные в базе данных https://pathogen.watch/ collection/ eurogasp2013. Всего в анализ включили 1071 изолят из 21 страны: Австрии, Бельгии, Великобритании, Венгрии, Германии, Греции, Дании, Ирландии, Исландии, Испании, Италии, Кипра, Латвии, Мальты, Нидерландов, Норвегии, Португалии, Словакии, Словении, Франции и Швеции. Данные по NG-MAST-типированию N. gonorrhoeae в Японии (2015 г.) были представлены сведениями о 206 клинических изолятах из базы данных https://pubmlst. org/ (нами выбраны образцы N. gonorrhoeae с известными вариантами porB и tbpB). Изоляты со смешанным или неопределенным NG-MAST-типом не учитывали. Таким образом, из исходной выборки (страны ЕС и Япония) было удалено 29 изолятов, что составило 1,4\% от всего объема выборки.

Для филогенетического анализа использовали конкатенированные последовательности генов рогв и tbpB. С использованием Байесовского критерия и информационного критерия Акаике было показано, что лучшая модель замен для наших данных - GTR с вычислением пропорции инвариантных сайтов и Г-моделью гетерогенной скорости. Для полученных последовательностей и выбранной модели методом максимального правдоподобия в программе RAxML вер. 7.4.8 [13] построено филогенетическое древо с числом итераций 999 на платформе http://galaxy-dev.cnsi.ucsb. edu/osiris/. Для построения древа использовали данные для российских и европейских клинических изолятов N. gonorrhoeae за 2013 г. Для клад на филогенетическом древе достоверными считали значения уровня поддержки (bootstrap value) 90\% и выше.

Данные по численности населения и доле изолятов уникальных сиквенс-типов по странам анализировали, используя иерархическую агломеративную кластеризацию методом Варда в пакете «cluster» для языка R. Для определения оптимального числа кластеров использовали пакет «Nbclust» [14]. Информация о численности населения стран и коэффициенты миграционного прироста (количество мигрантов на 1000 человек населения) взяты из The World Factbook, https://www.cia.gov/library/ publications/the-world-factbook/.

\section{РЕЗУЛЬТАТЫ ИССЛЕДОВАНИЯ}

По результатам молекулярного типирования, 822 клинических изолята N. gonorrhoeae, собранных в России в период с 2013 по 2018 г., были отнесены к 301 различному NG-MAST-типу. Наиболее распространенными сиквенстипами были 807, 228, 1993, 5714, 9476 (8,3\%; 3,3\%; $3,2 \% ; 3,2 \% ; 2,7 \%$ от общей численности анализируемой выборки соответственно). В 2013 г. изоляты NG-MAST 807 составляли более 13\% российской популяции N. gonorrhoeae, а далее их доля постепенно уменьшалась от года к году до 4,6\% в 2018 г. (см. табл. 1). Представители сиквенс-типов 807 и 1993 обнаружены также среди образцов, полученных в европейских странах, однако в Европе они встречались спорадически: NG-MAST 807 в Испании и Словакии и NG-MAST 1993 - в Дании. В 2018 г. на первом месте в России по распространенности оказался уникальный российский тип NG-MAST 228, сформировавший 14,6\% популяции. Доля российских изолятов, относящихся к уникальным российским сиквенстипам (см. табл. 1, отмечены звездочкой), в общем числе сохранялась (2013-2018) и в среднем составляла около 80\%.

Следует отметить высокую долю сиквенс-типов, представленных одним образцом, которая сохранялась год от года и равнялась 25-31\% от общего количества изолятов. Для образцов N. gonorrhoeae стран ЕС эта доля в 2013 г. составила 24\% [6].

Результаты молекулярного типирования N. gonorrhoeae в странах Европы [5, 6], а также наиболее часто встречающиеся сиквенс-типы представлены в табл. 2. В европейских странах в 2013 г. обнаружено 389 сиквенстипов, наиболее распространенным среди которых был NGMAST 1407, встречающийся в 13 странах и составивший 7,3\% от общей численности проанализированных клинических изолятов.

Популяция N. gonorrhoeae Японии (см. табл. 2) сильно отличалась как от российской, так и от европейской. Изоляты из Японии принадлежали к 65 молекулярным типам, из них только два сиквенс-типа присутствовали в России и в европейских странах: NG-MAST 1407 (в странах ЕС и в России) и NG-MAST 4186 (один образец этого типа в Швеции), остальные 63 молекулярных типа были уникальными для Японии.

Для определения филогенетического родства клинических изолятов N. gonorrhoeae Европы и России построено филогенетическое древо по максимальному правдоподобию. Филогенетическое древо с раскраской, соответствующей наличию NG-MAST-типа в той или иной стране, представлено на рис. 1.

Анализ расположения сиквенс-типов изолятов, полученных в России и Европе, на древе позволил выделить 16 клад с высокими значениями уровня поддержки (более 90\%) (см. рис. 1). Некоторые клады полностью либо частично соответствуют европейским геногруппам, установленным в докладе Европейского центра профилактики и контроля болезней для образцов N. gonorrhoeae, полученных в Европе в 2013 г. [6].

Клада а (уровень поддержки 100) включает 40 NGMAST-типов (82 изолята) из 17 стран Европы и России, из них 6 сиквенс-типов принадлежат 7 российским изолятам (8,5\%). Клада включает NG-MAST 5624 (15 образцов из 7 стран) и соответствует ранее установленной европейской геногруппе G5624 [6].

Клада $\beta$ (уровень поддержки 94) состоит из 33 сиквенстипов (91 изолят), включая часто встречающиеся в Европе NG-MAST 225 (24 образца из 12 европейских стран) и NG-MAST 292 (15 образцов из 6 стран, из них один образец из России). Российские образцы в данной кладе представлены 19 изолятами (21,3\%), принадлежащими к 12 сиквенс-типам. Клада $\beta$ соответствует европейской геногруппе G225 [6].

Клада Ү (уровень поддержки 96) состоит из 14 сиквенстипов (98 изолятов), полученных в 17 странах Европы (из 
Таблица 2. Наиболее часто встречающиеся NG-MAST-типы в странах EC и Японии

\begin{tabular}{|c|c|c|c|c|}
\hline $\begin{array}{c}\text { Страна } \\
\text { (код страны) }\end{array}$ & Год & $\begin{array}{c}\text { Число проанализированных клинических изолятов } \\
\text { (число выявленных сиквенс-типов) }\end{array}$ & $\begin{array}{c}\text { Наиболее распространенные } \\
\text { сиквенс-типы }\end{array}$ & $\begin{array}{c}\text { Доля образцов } \\
\text { данного сиквенс-типа, \% }\end{array}$ \\
\hline Австрия (АТ) & 2013 & $50(24)$ & $\begin{array}{c}3785^{\star} \\
11575^{\star} \\
387,4994\end{array}$ & $\begin{array}{c}18,0 \\
12,0 \\
8,0\end{array}$ \\
\hline Бельгия (BE) & 2013 & $55(24)$ & $\begin{array}{c}1407 \\
387,2992 \\
2400,5624\end{array}$ & $\begin{array}{c}16,4 \\
14,5 \\
7,3\end{array}$ \\
\hline Кипр (CY) & 2013 & $6(4)$ & $\begin{array}{c}1407 \\
4269,6146^{*}, 10803^{*}\end{array}$ & $\begin{array}{c}49 \\
17,0\end{array}$ \\
\hline Германия (DE) & 2013 & $45(30)$ & $\begin{array}{c}4995 \\
359,5441,9500^{*}\end{array}$ & $\begin{array}{l}8,9 \\
6,7\end{array}$ \\
\hline Дания (DK) & 2013 & $54(28)$ & $\begin{array}{l}1993 \\
1407 \\
2400\end{array}$ & $\begin{array}{l}20,4 \\
14,8 \\
7,4\end{array}$ \\
\hline Испания (ES) & 2013 & $110(64)$ & $\begin{array}{c}1407 \\
2400 \\
21\end{array}$ & $\begin{array}{c}10,0 \\
9,1 \\
7,3\end{array}$ \\
\hline Франция (FR) & 2013 & $56(40)$ & $\begin{array}{c}645 \\
4995,5624,11352^{*}\end{array}$ & $\begin{array}{l}8,9 \\
5,4\end{array}$ \\
\hline Греция (GR) & 2013 & $48(20)$ & $\begin{array}{c}3128 \\
225,4730,11055^{\star}\end{array}$ & $\begin{array}{l}18,8 \\
10,4\end{array}$ \\
\hline Венгрия (HU) & 2013 & $46(20)$ & $\begin{array}{c}1407 \\
995 \\
387,11046^{\star}\end{array}$ & $\begin{array}{l}21,7 \\
13,0 \\
6,5\end{array}$ \\
\hline Ирландия (IE) & 2013 & $44(26)$ & $\begin{array}{c}2992 \\
384 \\
21,225,437,649^{\star}, 2400,10843^{\star}, 10846^{\star}\end{array}$ & $\begin{array}{c}15,9 \\
11,4 \\
4,5\end{array}$ \\
\hline Исландия (IS) & 2013 & $5(5)$ & $1034,2400,9541^{*}, 10640^{\star}, 11080^{*}$ & 20,0 \\
\hline Италия (IT) & 2013 & $24(13)$ & $\begin{array}{c}2992 \\
6360 \\
5624,8826^{\star}\end{array}$ & $\begin{array}{c}33,3 \\
12,5 \\
8,3\end{array}$ \\
\hline Латвия (LV) & 2013 & $38(15)$ & $\begin{array}{c}5 \\
10828^{*} \\
21,4269\end{array}$ & $\begin{array}{c}36,8 \\
13,2 \\
7,9\end{array}$ \\
\hline Мальта (МТ) & 2013 & $20(10)$ & $\begin{array}{c}2992 \\
1407,484^{\star}, 9905^{\star}, 10788^{\star}\end{array}$ & $\begin{array}{l}35,0 \\
10,0\end{array}$ \\
\hline Нидерланды (NL) & 2013 & $66(38)$ & $\begin{array}{c}2992 \\
2400 \\
4995,5624,8154,8919\end{array}$ & $\begin{array}{c}13,6 \\
12,1 \\
4,5\end{array}$ \\
\hline Норвегия (NO) & 2013 & $55(41)$ & $\begin{array}{l}1407 \\
4275 \\
2400\end{array}$ & $\begin{array}{l}9,1 \\
7,3 \\
5,5\end{array}$ \\
\hline Португалия (РТ) & 2013 & $103(54)$ & $\begin{array}{l}1407 \\
7445 \\
1034\end{array}$ & $\begin{array}{c}16,5 \\
11,7 \\
4,9\end{array}$ \\
\hline Швеция (SE) & 2013 & $49(31)$ & $\begin{aligned} 5445 \\
3128,7164,7445\end{aligned}$ & $\begin{array}{c}10,2 \\
6,1\end{array}$ \\
\hline Словения (SI) & 2013 & $53(26)$ & $\begin{array}{c}21 \\
10800,10801^{\star} \\
10798^{\star}, 10799^{\star}\end{array}$ & $\begin{array}{c}13,2 \\
11,3 \\
7,5\end{array}$ \\
\hline Словакия (SK) & 2013 & 38 (19) & $\begin{array}{c}1407,10800,11042^{*} \\
359,2992\end{array}$ & $\begin{array}{l}13,2 \\
10,5\end{array}$ \\
\hline $\begin{array}{l}\text { Великобритания } \\
\text { (UK) }\end{array}$ & 2013 & $106(52)$ & $\begin{array}{c}2992 \\
51 \\
4995\end{array}$ & $\begin{array}{c}11,3 \\
10,4 \\
6,6\end{array}$ \\
\hline Польша (PL) & 2012 & - & $\begin{array}{c}1407 \\
8391^{\star} \\
1861,2992\end{array}$ & $\begin{array}{c}47,0 \\
7,0 \\
5,0\end{array}$ \\
\hline Япония (JP) & 2015 & 206 (65) & $\begin{array}{l}5687^{\star} \\
1407 \\
6778^{\star}\end{array}$ & $\begin{array}{l}7,8 \\
6,3 \\
4,4\end{array}$ \\
\hline
\end{tabular}

Примечание: * — NG-MAST-типы, уникальные для данной страны; ** — наиболее часто встречающиеся NG-MAST-типы для Польши, описанные в [17]. 
России - один изолят), из них 78 образцов принадлежат сиквенс-типу NG-MAST 2992 (2-е место в Европе по распространенности). Клада Ү соответствует европейской геногруппе G2992 [6].

Клада $\delta$ (уровень поддержки 98) включает 3 сиквенстипа (образцы из Португалии, Норвегии, Великобритании. Клада є (уровень поддержки 100) состоит из 4 сиквенстипов (4 изолята из Норвегии, Греции и Великобритании). Клада 弓 (уровень поддержки 100) включает только уникальные российские сиквенс-типы (7 образцов, принадлежащих 5 NG-MAST-типам).

Клады $\eta$ и $\theta$ (уровни поддержки 98 и 90 соответственно) включают только европейские сиквенс-типы, не обнаруженные в России. Клада п состоит из 9 NG-MASTтипов (16 образцов), клада $\theta-$ из 11 сиквенс-типов (34 образца). NG-MAST-типы этих двух клад принадлежат одной европейской геногруппе G5333 [6].

Клада เ (уровень поддержки 98) состоит из 4 сиквенстипов (4 образца, полученных в Португалии, Италии и Нидерландах).
Клада К (уровень поддержки 94) содержит 4 европейских сиквенс-типа (36 образцов), в том числе сиквенс-тип NG-MAST 4995 (4-е место в Европе по распространенности, обнаружен в 10 европейских странах), к которому принадлежит 31 изолят. Клада К соответствует европейской геногруппе G4995 [6].

В кладу $\lambda$ (уровень поддержки 95) входят 3 сиквенс-типа европейских стран: 10 образцов, из них 8 принадлежит NG-MAST 5441, обнаруженному в 5 странах.

Клада $\mu$ (уровень поддержки 94) состоит из 4 сиквенстипов (10 образцов, обнаруженных в Греции, Дании, Словении, Португалии). Клада v (уровень поддержки 98) включает 3 сиквенс-типа (5 образцов из 5 европейских стран).

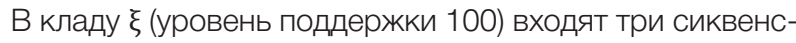
типа (4 образца из Ирландии и Дании). Клада о (уровень поддержки 98) состоит из 5 NG-MAST-типов (17 образцов), включающих часто встречающиеся в России типы NGMAST 1993 и 5714.

Клада $\pi$ (уровень поддержки 97) включает 7 сиквенстипов (12 изолятов), обнаруженных как в России, так и в

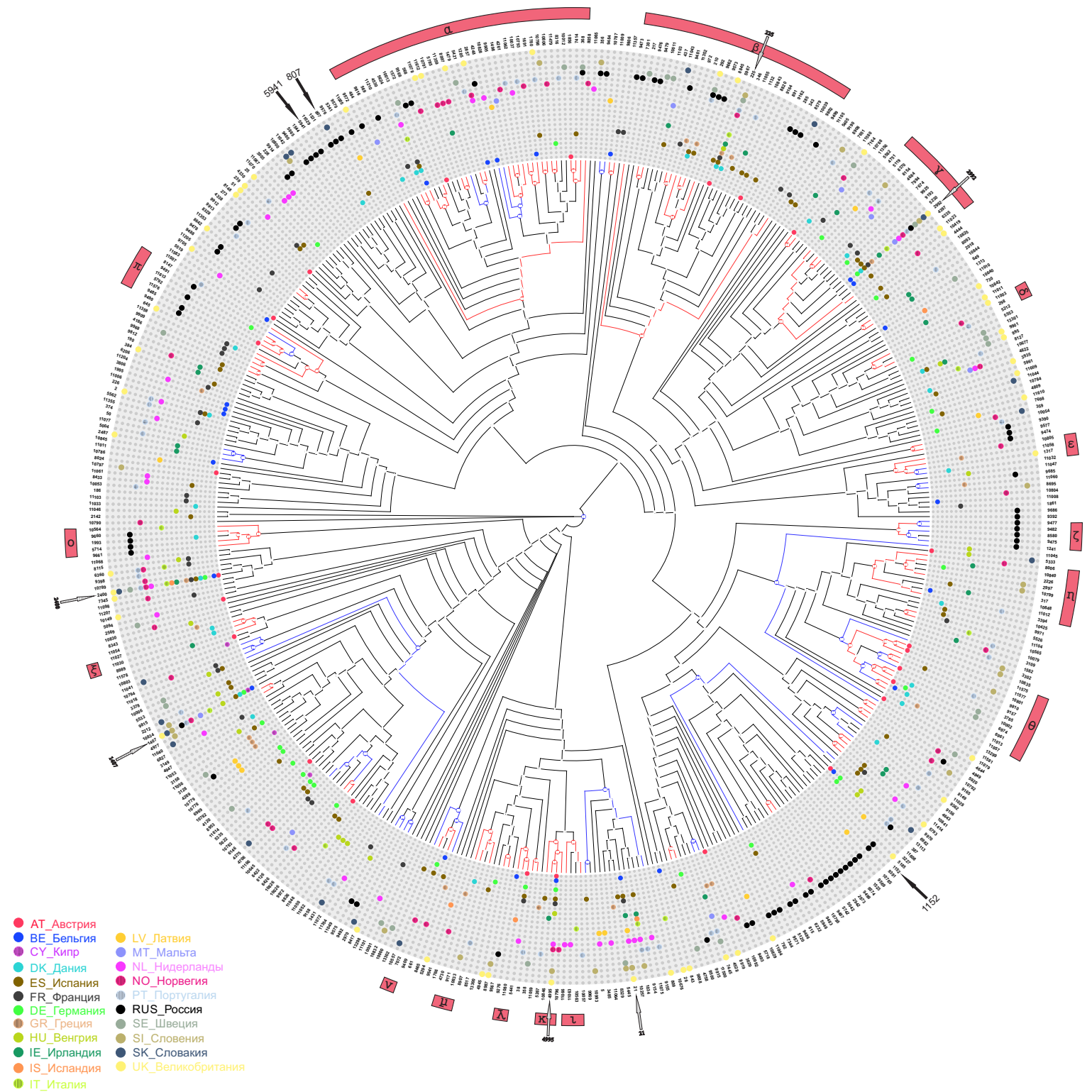

Рис. 1. Филогенетическое древо NG-MAST-типов N. gonorrhoeae, обнаруживаемых в России и странах ЕС. Синими линиями на древе обозначены ветви со значением уровня поддержки 80-89, красным - со значением уровня поддержки 90-100. Филогенетические клады (уровень поддержки $\geq 90 \%$ обозначены греческими буквами $\alpha-\pi$. Черными стрелками показаны NG-MAST-типы, наиболее часто встречающиеся в России, серыми заштрихованными стрелками NG-MAST-типы, наиболее распространенные в европейских странах 
европейских странах. Сюда входят уникальные российские сиквенс-типы NG-MAST 5792, 9485, 9490, 9491.

Для каждой страны были обнаружены изоляты, принадлежащие к уникальным сиквенс-типам, не найденным в других странах. Доля изолятов с уникальными сиквенс-типами от общего количества изолятов в стране в европейских странах варьировала от 25 до 56\%, наименьшие значения у Великобритании и Бельгии, наибольшие у Австрии, Словении, Швеции (> 50\%). Для России и Японии доля изолятов с уникальными сиквенстипами превышала 80\% (табл. 3).

Для нахождения групп со сходными параметрами распространения уникальных сиквенс-типов и их связи с численностью населения страны проведен кластерный анализ, включающий 21 страну (см. табл. 3). Из анализа были исключены Кипр и Исландия из-за малого количества доступных образцов (6 и 5 соответственно). После проведения иерархической кластеризации методом Варда оптимальное число кластеров определили с помощью пакета «NbClust» для языка $\mathrm{R}$, используя правило большинства. Девять методов (Silhouette, Duda, PseudoT2, Beale, Ratkowsky, PtBiserial, McClain, Dunn, SDindex) из 30 показали, что оптимально разбиение стран на два кластера (уровень значимости 0,01), шесть методов (Hartigan, Scott, Marriot, TrCovW, TraceW, Ball) показали, что оптимально разбиение на три кластера. В соответствии с правилом большинства было принято решение, что оптимальным является разбиение на два кластера, но в то же время имеется статистическое обоснование для разбиения кластера 2 на два подкластера (рис. 2А).

В первый кластер входят Россия и Япония - страны с населением свыше 125 млн человек, во второй - все европейские страны с населением 0,4-81 млн человек. Второй кластер подразделен на два подкластера 2а и 26; подкластер 2а включает Великобританию, Германию,
Испанию, Италию и Францию - страны с населением 47-81 млн человек, подкластер 26 включает европейские страны с численностью населения менее 17 млн человек (Ирландия, Норвегия, Дания, Словакия, Мальта, Латвия, Словения, Нидерланды, Бельгия, Португалия, Греция, Австрия, Венгрия, Швеция).

В целом, изолятов с уникальными сиквенс-типами тем больше, чем больше население страны, что видно на примере стран с численностью населения свыше 47 млн человек, входящих в кластер 1 и подкластер 2а (рис. 2Б). Для стран кластера 26 с меньшей численностью населения такой зависимости не наблюдается. Переход из кластера 2 в кластер 1 происходит для стран с численностью населения более 125 млн человек (Россия, Япония).

Интересно было также проанализировать вклад мобильности населения (миграции) в распределение образцов уникальных сиквенс-типов по странам. При анализе только коэффициентов миграции по странам и доли образцов уникальных сиквенс-типов не удалось выявить кластеры, подтверждаемые статистическими критериями. При кластерном анализе трех параметров (миграции населения, численности населения и доли образцов уникальных сиквенс-типов) коэфрфициент агломерации оказался равен 0,83, что ниже, чем коэффициент 0,93, полученный при анализе двух параметров: численности населения и доли образцов уникальных сиквенс-типов.

\section{ОБСУЖДЕНИЕ РЕЗУЛЬТАТОВ}

Сравнение результатов молекулярного типирования изолятов N. gonorrhoeae в России, странах Европы и в Японии показало существенные различия между популяциями гонококка. Большинство российских изолятов обладали сиквенстипами, не встречающимися в анализируемый период в европейских странах и Японии. Так, в России обнаружено

Таблица 3. Распределение образцов уникальных NG-MAST-типов по странам (2013 г.)

\begin{tabular}{|c|c|c|c|c|c|}
\hline Страна & $\begin{array}{c}\text { Число уникальных } \\
\text { сиквенс-типов }\end{array}$ & $\begin{array}{l}\text { Число изолятов } \\
\text { с уникальными } \\
\text { сиквенс-типами }\end{array}$ & $\begin{array}{c}\text { Доля изолятов с уникальными } \\
\text { сиквенс-типами от общего числа } \\
\text { образцов, \% }\end{array}$ & $\begin{array}{c}\text { Население, } \\
\text { тыс. чел. }\end{array}$ & $\begin{array}{l}\text { Коэффициент } \\
\text { миграционного } \\
\text { прироста }\end{array}$ \\
\hline Россия & 73 & 129 & 80,6 & 142500 & 1,69 \\
\hline Япония & 63 & 192 & 93,2 & 126920 & 0 \\
\hline Германия & 15 & 18 & 40,0 & 81147 & 0,89 \\
\hline Франция & 24 & 27 & 48,2 & 65952 & 1,10 \\
\hline Великобритания & 24 & 27 & 25,5 & 63396 & 2,57 \\
\hline Италия & 6 & 7 & 29,2 & 61482 & 4,47 \\
\hline Испания & 31 & 36 & 32,7 & 47370 & 6,14 \\
\hline Нидерланды & 18 & 19 & 28,8 & 16805 & 1,99 \\
\hline Португалия & 32 & 40 & 38,8 & 10799 & 2,82 \\
\hline Греция & 10 & 21 & 43,8 & 10773 & 2,32 \\
\hline Бельгия & 13 & 14 & 25,5 & 10444 & 1,22 \\
\hline Венгрия & 10 & 14 & 30,4 & 9939 & 1,36 \\
\hline Швеция & 19 & 25 & 51,0 & 9119 & 1,64 \\
\hline Австрия & 13 & 28 & 56,0 & 8222 & 1,78 \\
\hline Дания & 14 & 17 & 31,5 & 5556 & 2,30 \\
\hline Словакия & 9 & 13 & 34,2 & 5488 & 0,28 \\
\hline Ирландия & 12 & 15 & 34,1 & 4776 & 2,51 \\
\hline Норвегия & 20 & 21 & 38,2 & 4723 & 1,68 \\
\hline Латвия & 11 & 16 & 42,1 & 2178 & $-2,36$ \\
\hline Словения & 14 & 27 & 50,9 & 1993 & 0,38 \\
\hline Мальта & 5 & 8 & 40,0 & 411 & 1,99 \\
\hline
\end{tabular}


только 3 образца (0,4\%) пандемически значимого молекулярного типа 1407, который доминировал в Бельгии, Венгрии, Дании, Испании, Норвегии, Португалии, Словакии, а также в Японии. Следует отметить, что изолять этого молекулярного типа еще в 2010 г. составляли более 10\% во многих европейских странах, в том числе в Австрии, Бельгии, Великобритании, Голландии, Испании, Италии, Португалии, Румынии, Словении, Польше [15-17], Японии и США $[18,19]$. Этот сиквенс-тип представляет большую опасность, так как в нем обнаружены множественные детерминанты резистентности $\mathrm{K}$ антимикробным препаратам, включающие мозаичный тип пенициллинсвязывающего белка РВР2 и дополнительную мутацию остатка Ala501 в PBP2, вызывающие устойчивость к цефалоспоринам [16, 20, 21].

В России присутствовало только 3 образца N. gonorrhoeae NG-MAST типа $2992(0,4 \%)$ и 7 образцов типа 2400 (0.9\%), которые занимали второе и третье места по распространенности в Европе в 2013 г. (7,0 и 4,7\% соответственно). Напротив, в европейских странах не были обнаружены NG-MAST-типы 228, 5714, 1751, которые входили в число ключевых среди российских изолятов.

Сравнение с ситуацией в соседней с Россией Польше (данные по этой стране отсутствовали в базе данных EUROGASP и были взяты из работы [17]) показало, что распределение NG-MAST-типов в Польше ближе к европейским странам, чем к России, с доминированием NG-MAST 1407 (см. табл. 2).

Анализ филогенетического древа NG-MAST-типов клинических изолятов Европы и России демонстрирует, что популяция N. gonorrhoeae как в России, так и в Европе гетерогенна. Существуют сиквенс-типы, одновременно присутствующие в разных странах, и в то же время в одной стране обнаружены изоляты, принадлежащие к филогенетически неблизким кладам. Не наблюдается близкого ффилогенетического родства между наиболее распространенными европейскими сиквенс-типами NGMAST 1407, 2992, 2400, 4995, 21, 225, которые в сумме составляют более четверти (25,9\%) от всех европейских штаммов: данные сиквенс-типы филогенетически далеки друг от друга и распределены по всему древу. Следует также отметить отсутствие близкого родства между наиболее распространенными европейскими и российскими сиквенс-типами, такими как NG-MAST 807, 1152, 5941. На древе выделено 16 клад с высокими значениями уровня поддержки, которые полностью либо частично соответствуют европейским геногруппам [6].

Дальнейший филогенетический анализ NG-MAST-типов позволил заключить, что геограсически разделенные популяции N. gonorrhoeae эволюционируют относительно локально. Это может быть одной из причин различий в уровне и динамике заболеваемости гонококковой инфекцией в России и странах ЕС [22]: в России наблюдается тенденция к снижению заболеваемости гонореей $[9,23]$, при этом не обнаружено изолятов, обладающих устойчивостью к цефтриаксону (основной препарат, используемый для лечения гонореи) [9, 10].

Нами проанализирована связь между долей изолятов с уникальными сиквенс-типами и численностью населения страны, в которой их обнаружили. В России и Японии преобладающая доля изолятов (> 80\%) относилась к уникальным для данной страны NG-MASTтипам. Кластерный анализ данных по доле изолятов с уникальными сиквенс-типами, обнаруженными в данной стране, и численности населения страны показал существование двух кластеров: первый кластер включал Россию и Японию с численностью населения свыше 125 млн человек, второй - анализируемые европейские страны с численностью населения 0,4-81 млн человек. В целом, показана тенденция в распределении уникальных сиквенстипов: их доля тем выше, чем больше численность населения страны.

\section{ВЫВОДЫ}

NG-MAST-типирование российских клинических изолятов N. gonorrhoeae показало их существенное отличие от современных популяций возбудителей гонококковой инфекции в странах ЕС и Японии. Наиболее широко распространенные в России молекулярные типы NGMAST 807, 1152 и 5941 в других странах представлены спорадически, а NG-MAST 228, 5714 и 1751 вообще не обнаружены. За период 2013-2018 гг. в России выявлено только три образца пандемически значимого молекулярного типа 1407 (0,4\% от общей численности анализируемой
A

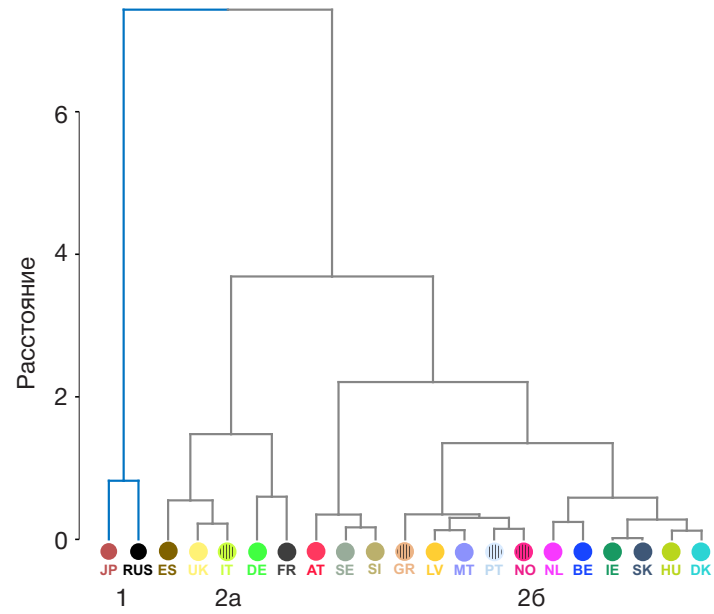

Б

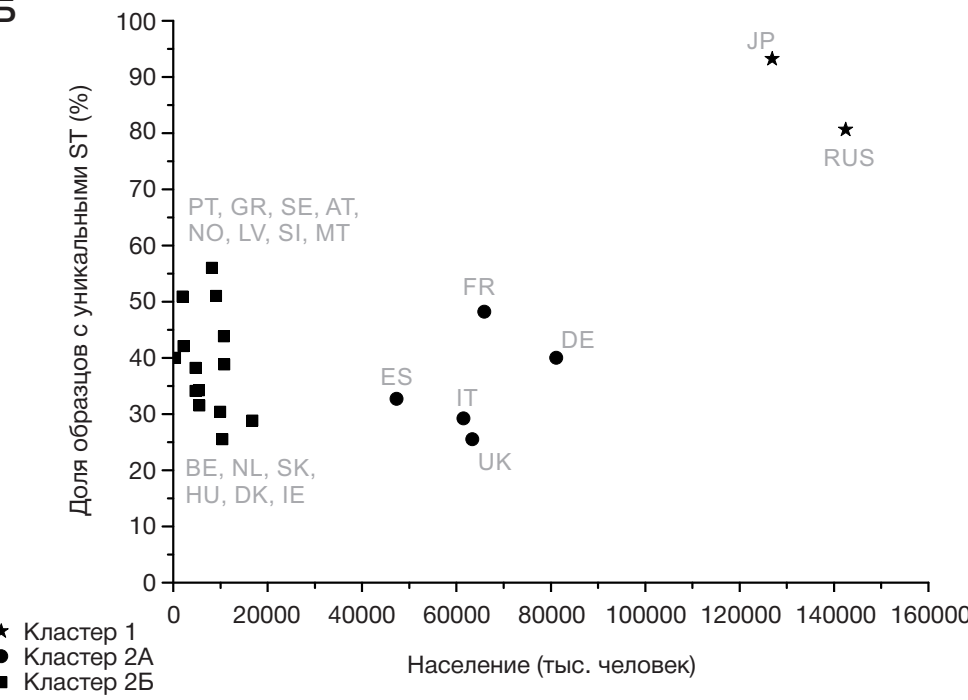

Рис. 2. Ассоциации между долей изолятов N. gonorrhoeae с уникальными сиквенс-типами и численностью населения стран, в которых они были обнаружены. Кодовые обозначения стран см. в табл. 1. А. Дендрограмма разбиения на кластеры. Выделенные кластеры обозначены цифрами. Б. Зависимость доли клинических изолятов N. gonorrhoeae, принадлежащих к уникальным сиквенс-типам, от численности населения 
выборки), который представляет большую опасность изза наличия множественных детерминант резистентности к антимикробным препаратам и доминирует во многих странах ЕС и Японии.

Филогенетический анализ NG-MAST-типов для изолятов России и стран ЕС показал их высокую генетическую гетерогенность, а также генетическую отдаленность распространенных европейских сиквенс-типов и сиквенстипов, наиболее часто встречающихся в России, что указывает на локальный характер формирования и эволюции российской популяции N. gonorrhoeae.

Преобладающая (> 80\%) доля российских и японских изолятов относилась к уникальным для данной странь NG-MAST-типам, что гораздо выше, чем доля изолятов уникальных типов в европейских странах. Кластерный анализ данных по доле изолятов с уникальными сиквенстипами и численности населения показал существование двух кластеров: Россия и Япония в одном и европейские страны в другом. При этом в странах с численностью населения более 47 млн человек (Великобритании, Германии, Испании, Италии, Франции, России и Японии) чем больше население, тем больше доля изолятов уникальных сиквенс-типов. Не удалось выявить зависимости доли изолятов с уникальными сиквенс-типами от миграции (мобильности) населения.

Таким образом, проведенный филогенетический анализ выявил относительную изолированность современной российской популяции N. gonorrhoeae, эволюционирующей на основе собственных закономерностей. Тем не менее сохраняется необходимость непрерывного динамического контроля за распространением гонококковой инфекции и антибиотикорезистентностью изолятов N. gonorrhoeae в РФ, целью которого являются своевременное выявление и эффективная элиминация глобально распространенных сиквенс-типов с множественными детерминантами резистентности.

\section{Литература}

1. Foxman B, Riley L. Molecular epidemiology: focus on infection. Am J Epidemiol. 2001; 153 (12): 1135-41. DOl: 10.1093/aje/153.12.1135.

2. Tacconelli E, Carrara E, Savoldi A, Harbarth S, Mendelson M, Monnet DL, et al. Discovery, research, and development of new antibiotics: the $\mathrm{WHO}$ priority list of antibiotic-resistant bacteria and tuberculosis. Lancet Infect Dis. 2018; 18 (3): 318-27. DOI: 10.1016/S1473-3099(17)30753-3.

3. Unemo M, Dillon JA. Review and international recommendation of methods for typing Neisseria gonorrhoeae isolates and their implications for improved knowledge of gonococcal epidemiology, treatment, and biology. Clin Microbiol Rev. 2011; (24): 447-58. DOI: 10.1128/CMR.00040-10.

4. Town K, Bolt H, Croxford S, Cole M, Harris S, Field N, et al. Neisseria gonorrhoeae molecular typing for understanding sexual networks and antimicrobial resistance transmission: A systematic review. J Infect. 2018; (76): 507-14. DOI: 10.1016/j. jinf.2018.02.011.

5. Harris SR, Cole MJ, Spiteri G, Sánchez-Busó L, Golparian D, Jacobsson $S$, et al. Public health surveillance of multidrugresistant clones of Neisseria gonorrhoeae in Europe: a genomic survey. Lancet Infect Dis. 2018; 18 (7): 758-68. DOI: 10.1016/ S1473-3099(18)30225-1.

6. European Centre for Disease Prevention and Control. Technical Report. Molecular typing of Neisseria gonorrhoeae - a study of 2013 isolates. Stockholm: ECDC; 2018. Available from: https:// www.ecdc.europa.eu/sites/portal/files/documents/Molecular-typing$\mathrm{N}$-gonorrhoeae-web.pdf.

7. Ilina EN, Oparina NY, Shitikov EA, Borovskaya AD, Govorun VM. Molecular surveillance of clinical Neisseria gonorrhoeae isolates in Russia. J Clin Microbiol. 2010; 48 (10): 3681-89. DOI: 10.1128/ JCM.00565-10.

8. Шпилевая М. В., Образцова О. А., Честков А. В. Использование методов генотипирования Neisseria gonorrhoeae. Вестник дерматологии и венерологии. 2015; (6): 33-40. DOI: 10.25208/0042-4609-2015-0-6-33-40.

9. Kubanov A, Solomka V, Plakhova X, Chestkov A, Petrova N, Shaskolskiy B, et al. Summary and trends of the Russian Gonococcal Antimicrobial Surveillance Programme, 20052016. J Clin Microbiol. 2019; 5 (6): e02024-18. DOI: 10.1128/ JCM.02024-18.

10. Shaskolskiy B, Dementieva E, Kandinov I, Filippova M, Petrova N, Plakhova X, et al. Resistance of Neisseria gonorrhoeae isolates to beta-lactam antibiotics (benzylpenicillin and ceftriaxone) in Russia, 2015-2017. PLoS One. 2019; 14 (7): e0220339. DOI: 10.1371/ journal.pone.0220339.

11. Воробьев Д. В., Соломка В. С., Плахова К. И., Дерябин Д. Г., Кубанов A. A. NG-MAST генотипирование штаммов Neisseria

gonorrhoeae, выделенных на территории Российской Федерации в 2012-2015 годах. Журнал Микробиологии, эпидемиологии и иммунобиологии. 2016; (4): 42-51.

12. Martin IMC, Ison CA, Aanensen DM, Fenton KA, Sprat BG. Rapid sequence-based identification of gonococcal transmission clusters in a large metropolitan area. J Infect Dis. 2004; (189): 1497-505. DOI: 10.1086/383047.

13. Stamatakis A. Using RAxML to infer phylogenies. Curr Protoc Bioinformatics. 2015; 51 (1): 6.14.1-14.14. DOI: 10.1002/0471250953.bi0614s51.

14. Charrad M, Ghazzali N, Boiteau V, Niknafs A. NbClust: an R package for determining the relevant number of clusters in a data set. Journal of Statistical Software. 2014; 61 (6): 1-36, DOI: 10.18637/jss.v061.i06.

15. European Centre for Disease Prevention and Control. Technical Report. Molecular typing of Neisseria gonorrhoeae — results from a pilot study 2010-2011. Stockholm: ECDC; 2012. Available from: https://www.ecdc.europa.eu/sites/portal/files/media/en/publications/ Publications/201211109-Molecular-typing-gonorrhea.pdf.

16. Chisholm SA, Unemo M, Quaye N, Johansson E, Cole MJ, Ison CA, et al. Molecular epidemiological typing within the European Gonococcal Antimicrobial Resistance Surveillance Programme reveals predominance of a multidrug-resistant clone. Euro Surveill. 2013; 18 (3): pii 20358. DOI: 10.2807/ese.18.03.20358-en.

17. Mlynarczyk-Bonikowska B, Malejczyk M, Majewski S, Unemo M. Antibiotic resistance and NG-MAST sequence types of Neisseria gonorrhoeae isolates in Poland compared to the world. Postepy Dermatol Alergol. 2018; 5 (6): 346-51. DOI: 10.5114/ ada.2018.79780.

18. Shimuta K, Watanabe Y, Nakayama S, Morita-Ishihara T, Kuroki T, Unemo $\mathrm{M}$, et al. Emergence and evolution of internationally disseminated cephalosporin-resistant Neisseria gonorrhoeae clones from 1995 to 2005 in Japan. BMC Infect Dis. 2015; (15): 378. DOI: 10.1186/s12879-015-1110-x.

19. Pandori M, Barry PM, Wu A, Ren A, Whittington WL, Liska S, et al. Mosaic penicillin-binding protein 2 in Neisseria gonorrhoeae isolates collected in 2008 in San Francisco, California. Antimicrob Agents Chemother. 2009; (53): 4032-34. DOI: 10.1128/ AAC.00406-09.

20. Unemo M, Shafer WM. Antimicrobial resistance in Neisseria gonorrhoeae in the 21st century: past, evolution, and future. Clin Microbiol Rev. 2014; 27 (3): 587-613. DOI: 10.1128/CMR.00010-14.

21. Unemo M. Current and future antimicrobial treatment of gonorrhoea - the rapidly evolving Neisseria gonorrhoeae continues to challenge. BMC Infect Dis. 2015; (15): 364. DOI: 10.1186/s12879-015-1029-2.

22. European Centre for Disease Prevention and Control. Gonorrhoea. 
Annual epidemiological report for 2017. Stockholm: ECDC; 2019. Available from: https://www.ecdc.europa.eu/sites/default/files/ documents/gonorrhoea-annual-epidemiological-report-2017.pdf.

23. Кубанова А. А., Кубанов А. А., Мелехина Л. Е., Богданова Е. В.
Результаты деятельности медицинских организаций дерматовенерологического профиля, достигнутые в 2016 г. Вестник дерматологии и венерологии. 2017; (4): 12-27. DOI: 10.25208/0042-4609-2017-0-4-20-21.

\section{References}

1. Foxman B, Riley L. Molecular epidemiology: focus on infection. Am J Epidemiol. 2001; 153 (12): 1135-41. DOI: 10.1093/aje/153.12.1135.

2. Tacconelli E, Carrara E, Savoldi A, Harbarth S, Mendelson M, Monnet DL, et al. Discovery, research, and development of new antibiotics: the $\mathrm{WHO}$ priority list of antibiotic-resistant bacteria and tuberculosis. Lancet Infect Dis. 2018; 18 (3): 318-27. DOI: 10.1016/S1473-3099(17)30753-3.

3. Unemo M, Dillon JA. Review and international recommendation of methods for typing Neisseria gonorrhoeae isolates and their implications for improved knowledge of gonococcal epidemiology, treatment, and biology. Clin Microbiol Rev. 2011; (24): 447-58. DOI: 10.1128/CMR.00040-10.

4. Town K, Bolt H, Croxford S, Cole M, Harris S, Field N, et al. Neisseria gonorrhoeae molecular typing for understanding sexual networks and antimicrobial resistance transmission: A systematic review. J Infect. 2018; (76): 507-14. DOI: 10.1016/j. jinf.2018.02.011.

5. Harris SR, Cole MJ, Spiteri G, Sánchez-Busó L, Golparian D, Jacobsson $S$, et al. Public health surveillance of multidrugresistant clones of Neisseria gonorrhoeae in Europe: a genomic survey. Lancet Infect Dis. 2018; 18 (7): 758-68. DOI: 10.1016/ S1473-3099(18)30225-1.

6. European Centre for Disease Prevention and Control. Technical Report. Molecular typing of Neisseria gonorrhoeae - a study of 2013 isolates. Stockholm: ECDC; 2018. Available from: https:// www.ecdc.europa.eu/sites/portal/files/documents/Molecular-typing$\mathrm{N}$-gonorrhoeae-web.pdf.

7. Ilina EN, Oparina NY, Shitikov EA, Borovskaya AD, Govorun VM. Molecular surveillance of clinical Neisseria gonorrhoeae isolates in Russia. J Clin Microbiol. 2010; 48 (10): 3681-89. DOI: 10.1128/ JCM.00565-10.

8. Shpilevaya MV, Obraztsova OA, Chestkov AV. The use of current genotyping assay methods for Neisseria gonorrhoeae. Vestnik Dermatologii i Venerologii. 2015; (6): 33-40. DOI: 10.25208/00424609-2015-0-6-33-40. Russian.

9. Kubanov A, Solomka V, Plakhova X, Chestkov A, Petrova N, Shaskolskiy B, et al. Summary and trends of the Russian Gonococcal Antimicrobial Surveillance Programme, 20052016. J Clin Microbiol. 2019; 5 (6): e02024-18. DOI: 10.1128/ JCM.02024-18.

10. Shaskolskiy B, Dementieva E, Kandinov I, Filippova M, Petrova N, Plakhova X, et al. Resistance of Neisseria gonorrhoeae isolates to beta-lactam antibiotics (benzylpenicillin and ceftriaxone) in Russia, 2015-2017. PLoS One. 2019; 14 (7): e0220339. DOI: 10.1371/ journal.pone.0220339.

11. Vorobiev DV, Solomka VS, Plakhova KI, Deryabin DG, Kubanov AA. NG-MAST genotyping of Neisseria gonorrhoeae strains isolated in Russian Federation in 2012-2015. Journal of microbiology, epidemiology, immunobiology. 2016; (4): 42-51. Russian.

12. Martin IMC, Ison CA, Aanensen DM, Fenton KA, Sprat BG.

Rapid sequence-based identification of gonococcal transmission clusters in a large metropolitan area. J Infect Dis. 2004; (189): 1497-505. DOI: 10.1086/383047.

13. Stamatakis A. Using RAxML to infer phylogenies. Curr Protoc Bioinformatics. 2015; 51 (1): 6.14.1-14.14. DOI: 10.1002/0471250953.bi0614s51.

14. Charrad M, Ghazzali N, Boiteau V, Niknafs A. NbClust: an R package for determining the relevant number of clusters in a data set. Journal of Statistical Software. 2014; 61 (6): 1-36, DOI: 10.18637/jss.v061.i06.

15. European Centre for Disease Prevention and Control. Technical Report. Molecular typing of Neisseria gonorrhoeae — results from a pilot study 2010-2011. Stockholm: ECDC; 2012. Available from: https://www.ecdc.europa.eu/sites/portal/files/media/en/publications/ Publications/201211109-Molecular-typing-gonorrhea.pdf.

16. Chisholm SA, Unemo M, Quaye N, Johansson E, Cole MJ, Ison CA, et al. Molecular epidemiological typing within the European Gonococcal Antimicrobial Resistance Surveillance Programme reveals predominance of a multidrug-resistant clone. Euro Surveill. 2013; 18 (3): pii 20358. DOI: 10.2807/ese.18.03.20358-en.

17. Mlynarczyk-Bonikowska B, Malejczyk M, Majewski S, Unemo M. Antibiotic resistance and NG-MAST sequence types of Neisseria gonorrhoeae isolates in Poland compared to the world. Postepy Dermatol Alergol. 2018; 5 (6): 346-51. DOI: 10.5114/ ada.2018.79780

18. Shimuta K, Watanabe Y, Nakayama S, Morita-Ishihara T, Kuroki T, Unemo $\mathrm{M}$, et al. Emergence and evolution of internationally disseminated cephalosporin-resistant Neisseria gonorrhoeae clones from 1995 to 2005 in Japan. BMC Infect Dis. 2015; (15): 378. DOI: 10.1186/s12879-015-1110-x.

19. Pandori M, Barry PM, Wu A, Ren A, Whittington WL, Liska S, et al. Mosaic penicillin-binding protein 2 in Neisseria gonorrhoeae isolates collected in 2008 in San Francisco, California. Antimicrob Agents Chemother. 2009; (53): 4032-34. DOI: 10.1128/ AAC.00406-09.

20. Unemo M, Shafer WM. Antimicrobial resistance in Neisseria gonorrhoeae in the 21st century: past, evolution, and future. Clin Microbiol Rev. 2014; 27 (3): 587-613. DOl: 10.1128/CMR.00010-14.

21. Unemo M. Current and future antimicrobial treatment of gonorrhoea - the rapidly evolving Neisseria gonorrhoeae continues to challenge. BMC Infect Dis. 2015; (15): 364. DOI: 10.1186/s12879-015-1029-2.

22. European Centre for Disease Prevention and Control. Gonorrhoea. Annual epidemiological report for 2017. Stockholm: ECDC; 2019. Available from: https://www.ecdc.europa.eu/sites/default/files/ documents/gonorrhoea-annual-epidemiological-report-2017.pdf.

23. Kubanova AA, Kubanov AA, Melekhina LE, Bogdanova EV. Results of work of dermatovenereologic healthcare organizations in 2016. Vestnik Dermatologii i Venerologii. 2017; (4): 12-27. DOI: 10.25208/0042-4609-2017-0-4-20-21. Russian. 